\section{Imaginary, tourism}

\author{
Noel B. Salazar
}

Cultural Mobilities Research, University of Leuven, Leuven, Belgium

It is hard to imagine tourism without the creative use of tempting as well as restrictive imaginaries of both peoples and places. Tourism imaginaries are socially transmitted representational assemblages that interact with people's personal imaginings and are used as meaning-making and world-shaping devices in tourism and beyond.

Scholars from a wide array of disciplines have given $>$ attention to the human capacity to imagine. Although imaginaries influence collective behavior, they are not necessarily an acknowledged part of public discourse or coterminous with implicit or covert culture. They are unspoken schemas of $>$ interpretation, rather than explicit ideologies (Salazar 2012). Many imaginaries are structured by dichotomies, sometimes difficult to discern in practice, that represent the world in simplified oppositional binaries (nature-culture, here-there, male-female, inside-outside, and local-global) as can be seen, for example, in the language of guidebooks.

In common with other human activities, tourism involves the capacity to imagine or to enter into the imaginings of others. Imaginaries come to occupy a central position in a complex set of connections among diverse societies, dissimilar places, and different kinds of relations of production and consumption. Stories, images, and desires, running the gamut from essentialized, mythologized, and exoticized imaginaries of Otherness to more realistic frames of reference, often function as the motor setting tourism in motion (Skinner and Theodossopoulos 2011). Marketers rely on imaginaries to represent and sell dreams of the world's limitless destinations, activities, types of $>$ accommodation, and peoples to discover and experience. Seductive images and discourses about peoples and places are so predominant that without them there probably would be little tourism, if any at all. They resonate most clearly in destinations, the physical and mental landscapes where the imaginaries of residents, tourism $>$ service providers, and tourists meet and, occasionally, clash (Graburn and Gravari-Barbas 2011).

By their very nature, imaginaries remain intangible, so the only way to study them is by focusing on the multiple conduits through which they pass and become visible in the form of verbal and nonverbal images (Salazar 2010). The in-depth study of tourism imaginaries - tracing their historical and semiotic roots while keeping the material effects of the processes in view - reveals that they are potent catalysts of sociocultural and environmental change and essential elements in the process of $\checkmark$ identity formation, the making of place, and the perpetual invention of $>$ culture (Salazar and Graburn 2014). Since they are grounded in 
relations of power, tourism imaginaries are never neutral. Rather, they renegotiate political and social realities. Their critical analysis offers a powerful deconstruction device of the ideological, political, and sociocultural stereotypes and clichés operating in tourism.

See also $>$ Anthropology, $\triangleright$ ideology, $\triangleright$ image, $>$ multidisciplinarity, $>$ theory.

\section{References}

Graburn, N., and M. Gravari-Barbas 2011 Imagined Landscapes of Tourism. Journal of Tourism and Cultural Change 9:159-269.

Salazar, N. 2010 Envisioning Eden: Mobilizing Imaginaries in Tourism and Beyond. Oxford: Berghahn.

Salazar, N. 2012 Tourism Imaginaries: A Conceptual Approach. Annals of Tourism Research 39:863-882.

Salazar, N., and N. Graburn, eds. 2014 Tourism Imaginaries: Anthropological Approaches. Oxford: Berghahn.

Skinner, J., and D. Theodossopoulos, eds. 2011 Great Expectations: Imagination and Anticipation in Tourism. Oxford: Berghahn. 